inversely with the extent of species hydration. For aldehydes where gem-diol formation is extensive (i.e. chloral) the reaction mechanism includes the gem-diol species and is shown as Mechanism 1, Figure 3.

It has already been shown with dissolved 1'10-phenanthroline, that the decomposition of $\left(\mathrm{FeO}_{4}\right)^{2-}$ proceeds via iron(IV) and iron(II) ${ }^{(5,6)}$.

With aldehydes where the extent of hydration is small (i.e. trimethylacetaldehyde) the dependency of the reaction mechanism on the $\mathrm{H}^{+}$concentration is large, see Mechanism 2, Figure 4. In Mechanisms 1 and 2, the iron species is protonated on the oxygen atom.

In both mechanisms the iron(II) species is oxidized to iron(III) by molecular oxygen dissolved in solution. The iron(III) form will separate by forming a gel if no complexing agent (i.e. phosphate buffers) are present in solution. The equilibrium oxidation state of the iron in an oxygenated reaction solution is iron(III). The rate of separation of the $\mathrm{Fe}_{2} \mathrm{O}_{3} \cdot \mathrm{x} \mathrm{H}_{2} \mathrm{O}$ gel is dependent on electrolytes dissolved in solution, the amount of $\mathrm{FeO}_{4}^{2-}$ initially present, and the suspended solids ${ }^{(2)}$.

\section{Experimental}

\section{Synthesis of potassium ferrate}

Iron(III) was oxidized by very alkaline $\mathrm{NaOCl}$ to produce research grade $\mathrm{K}_{2} \mathrm{FeO}_{4}$ of $99 \%$ purity.

\section{Instruments}

Spectrophotometers used in this work included the Beckman 26 and Cary Model 14. Data was analyzed by Cornell Algorithm on a Horizon Northstar Microcomputer. Quartz cells $(10 \mathrm{~cm}$ length $)$ in length were used in an incubated carriage.

\section{Measurement of ferrate decomposition}

Reagents (at least analytical grade) were correctly stored in glass containers. Dry solids were weighed on an analytical balance to parts per thousand and liquid vol. were measured by analytical pipettes or burettes. Reactions were monitored at $505 \mathrm{~nm}$. Aldehyde concentrations were in great excess over concentrations of $\left(\mathrm{FeO}_{4}\right)^{2-}$ in order to adhere to pseudo-first order conditions.

Phosphate buffers were used at a concentration greater than $0.4 \mathrm{M}$ in order to maintain constant $\mathrm{pH}$ during the course of reaction. The $\mathrm{K}_{2} \mathrm{FeO}_{4}$ concentration was $1.01 \times 10^{-4}$ molar. With distilled $\mathrm{H}_{2} \mathrm{O}$ as a blank, the experimental solution consisted of buffer and substrate (aldehyde) added to a preweighed mass of solid dry $\mathrm{K}_{2} \mathrm{FeO}_{4}$. Upon mixing, a strip chart recorder was started and absorbance was monitored as a function of time. For reaction times greater than 10 half-lives an equilibrium absorbance reading was taken and used in the Cornell method.

\section{References}

(1) R. G. Cornell, Biometrics, 18, 104 (1962). - ${ }^{(2)}$ R. K. Murmann and P. R. Robinson, Water Research, 8, 543 (1974). - ${ }^{(3)}$ N. Allinger and A. Johnson, Organic Chemistry, Worth Publishers, New York, 1976. -

(4) K. Wiberg, Oxidation in Organic Chemistry, Academic Press, New York City, 1965. - ${ }^{(5)}$ R. Bartzatt, The Kinetics of Oxidation of Vari ous Organic Substrates by Potassium Ferrate, Ph.D. Thesis, University of Nebraska-Lincoln, Lincoln, Nebraska, 1982. $-{ }^{(6)} \mathrm{R}$. Bartzatt, A. Tabatabai and J. Carr, Synth. React. Inorg. Met.-Org. Chem., 15, 1171 (1985)

(Received March 26th, 1986)

TMC 1526

\title{
Far-Infrared and Raman Spectra of Pseudo-Tetrahedral Complexes of Ethylenedimorpholene
}

\author{
Paul G. Rasmussen \\ Department of Chemistry, University of Michigan, Ann Arbor, MI 48109 U.S.A.
}

\section{Summary}

The far-i.r. and Raman spectra of a closely related group of pseudo-tetrahedral complexes of general formula [ $\left.\mathrm{MX}_{2} \mathrm{EDM}\right]$ are reported $\left(\mathrm{M}=\mathrm{Co}^{\mathrm{II}}, \mathrm{Ni}^{\mathrm{II}}, \mathrm{Cu}^{\mathrm{II}}, \mathrm{Zn}^{\mathrm{II}} ; \mathrm{X}=\mathrm{Cl}\right.$ or $\left.\mathrm{Br}\right)$. EDM, ethylenedimorpholene, acts in these compounds as a bidentate nitrogen donor. The main skeletal vibrations are assigned under the approximate symmetry of the $C_{2 v}\left(\mathrm{MX}_{2} \mathrm{Y}_{2}\right)$ point group.

\section{Introduction}

Vibrational spectroscopy is a very useful tool for characterizing structural aspects of metal complexes if appropriate group frequencies are available for comparison. The main metal-to-ligand modes, which are generally in the far i.r. region, are particularly useful and can easily be observed with modern instrumentation. However, assignments in this region are often less reliable than those at higher wavelength because group frequencies overlap and shift more ${ }^{(1)}$. Thus a complete assignment of the vibrational bands in a complex is desirable. This information is quite easily obtained when the symmetry is high but is much more difficult when the symmetry is low and the ligands become more complicated. We report here firm assignments for the main skeletal vibrations in pseudo-tetrahedral complexes treated as having $C_{2 v}$ symmetry $\left(\mathrm{MX}_{2} \mathrm{Y}_{2}\right)$ where $\mathrm{X}$ is halogen, and $\mathrm{Y}$ is a nitrogen of the bidentate ligand ethylenedimorpholene (EDM). Although the true symmetry is only $C_{2}$, the analysis is greatly aided in this case by having a more complicated ligand which forces four coordinate 
Table 1. Frequency assignments $\left(\mathrm{cm}^{-1}\right)$.

\begin{tabular}{llr}
\hline$v_{1}$ & $\mathrm{Zn}-\mathrm{N}_{2}$ & 324 \\
$v_{6}$ & $\mathrm{Zn}-\mathrm{N}_{2}$ & 296 \\
$v_{3}$ & $\mathrm{Zn}-\mathrm{Cl}_{2}$ & 305 \\
$v_{3}$ & $\mathrm{Zn}-\mathrm{Br}_{2}$ & 209 \\
$v_{4}$ & $\mathrm{Zn}-\mathrm{Cl}_{2}$ & 100 \\
$v_{4}$ & $\mathrm{Zn}-\mathrm{Br}_{2}$ & 73 \\
$v_{9}$ & $\mathrm{Zn}-\mathrm{Cl}_{2}$ & 333 \\
$v_{9}$ & $\mathrm{Zn}-\mathrm{Br}_{2}$ & 247 \\
\hline
\end{tabular}

geometry in a series of cases: $\mathrm{M}=$ cobalt(II), nickel(II), copper(II) and zinc(II).

The earliest extensive examination of vibrations in complexes of this type was due to Clark and Williams ${ }^{(2)}$. In their classic paper they analyzed the spectra, mostly of pyridine derivatives of metal halides. However, instrument limitations at that time prevented them from going below $200 \mathrm{~cm}^{-1}$ and they were unable to make complete use of the assignments of Sabatini and Sacconi on tetrahalo-complexes ${ }^{(3)}$ whose work extended to $70 \mathrm{~cm}^{-1}$. Nakamoto and coworkers ${ }^{(4)}$ provided a more complete vibrational analysis for mixed complexes $\left[\mathrm{Zn}(\mathrm{py})_{2} \mathrm{X}_{2}\right]$ (py = pyridine) by using isotopically pure ${ }^{64} \mathrm{Zn}$, ${ }^{68} \mathrm{Zn}$ and perdeuterio-pyridine. They also used both Raman and far-i.r. spectra for their analysis. Our investigation is in substantial agreement with this work, but provides results for more metals and extends the analysis to the experimentally important case of a bidentate amine-type ligand. This latter change results in at least one significant shift in stretching frequency.

\section{Results and Discussion}

Ethylenedimorpholene can be considered as a highly hindered $N$-substituted ethylenediamine. In its most stable conformation the morpholene rings offer nearly complete blocking to the cis positions of an octahedral complex once a metal ion is coordinated to the amine nitrogens. Thus as a ligand it is highly forcing towards pseudo-tetrahedral geometry, as we have shown in earlier work ${ }^{(5)}$. Furthermore, we have demonstrated that a large group of complexes using different metals and various halide species are isomorphous to the solved crystal structure of $\left[\mathrm{Co}(\mathrm{EDM}) \mathrm{Cl}_{2}\right]^{(6)}$. Thus we are afforded the opportunity to study the vibrational spectra of a structurally known and closely similar group of complexes. EDM is very close in mass to two pyridines and may have similar $\mathrm{M}-\mathrm{N}$ stretching frequencies.

We begin the analysis by treating the complexes as $\left[\mathrm{MX}_{2} \mathrm{Y}_{2}\right]$ units of $C_{2 v}$ symmetry. The nine normal modes and their frequency assignments for this five-atom unit have been described by Herzberg ${ }^{(7)}$ for $\mathrm{CH}_{2} \mathrm{Cl}_{2}$, by LeComte $^{(8)}$ for $\mathrm{CCl}_{2} \mathrm{Br}_{2}$, by Stammreich ${ }^{(9)}$ and Miller ${ }^{(10)}$ for $\mathrm{CrO}_{2} \mathrm{Cl}_{2}$, and by Alderdice ${ }^{(11)}$ for $\mathrm{CrO}_{2} \mathrm{~F}_{2}$. All nine modes are Raman active and all but $v_{5}\left(a_{2}\right)$ torsion are i.r. active. We follow Herzberg in the designations of the modes. In this scheme $v_{1}\left(a_{1}\right), v_{2}\left(a_{1}\right)$, $v_{6}\left(b_{1}\right)$ and $v_{3}\left(a_{1}\right), v_{4}\left(a_{1}\right), v_{9}\left(b_{2}\right)$ are the symmetric stretch, symmetric bend, and asymmetric stretch of the light and heavy atoms, respectively. The two rocking modes $v_{7}\left(b_{1}\right)$ and $v_{8}\left(b_{2}\right)$ and the torsional $v_{5}\left(\mathrm{a}_{2}\right)$ cannot be localized in a particular group.

The i.r. data are presented in Figure 1. The utility of comparing a closely similar set of metal complexes is apparent since small shifts reveal the presence of overlapping peaks. The bromide spectra clarify further that the $\mathrm{M}-\mathrm{N}$ and $\mathrm{M}-\mathrm{Cl}$ peaks are overlapping. The $v(\mathrm{Br}) / v(\mathrm{Cl})$ ratio is close to the

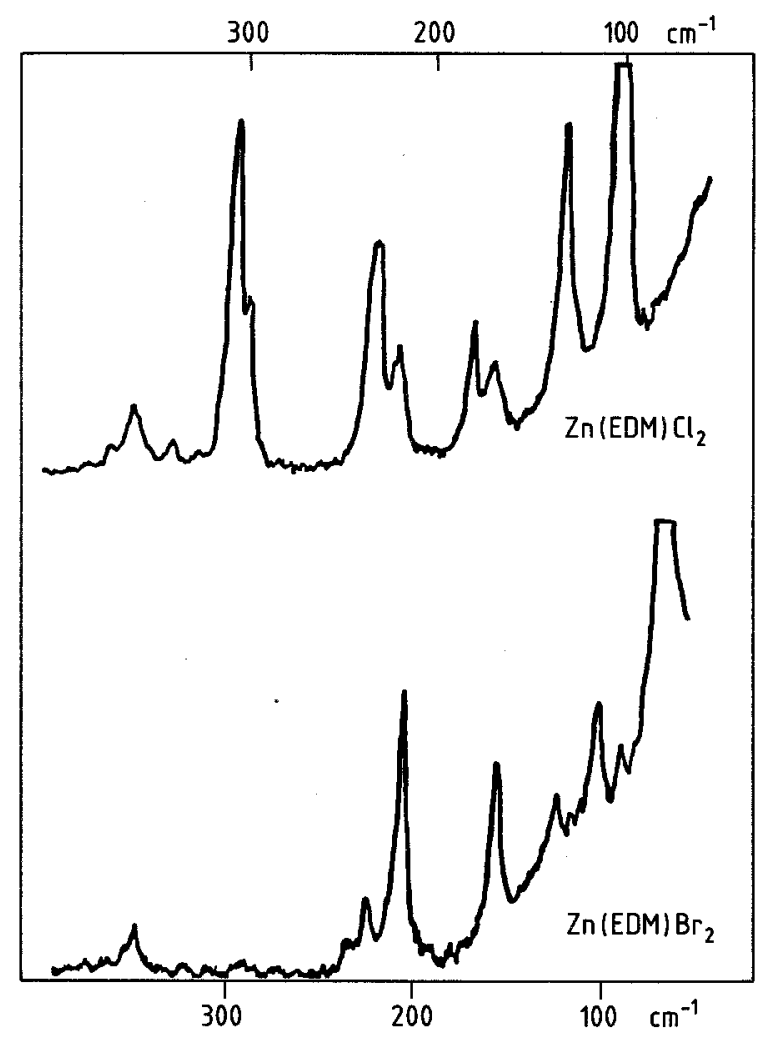

Figure 1. I.r. spectra.

expected $0.77^{(12)}$. In the Raman data presented in Figure 2 it is easy to identify $v_{4}$ (halogen bend) from its high intensity and mass shift $\left(\mathrm{Cl}-\mathrm{M}-\mathrm{Cl}=100 \mathrm{~cm}^{-1}, \mathrm{Br}-\mathrm{M}-\mathrm{Br}=73 \mathrm{~cm}^{-1}\right)$. The $\mathrm{M}-\mathrm{X}$ symmetric and antisymmetric stretches should have opposite relative intensities in the i.r. and Raman spectra and

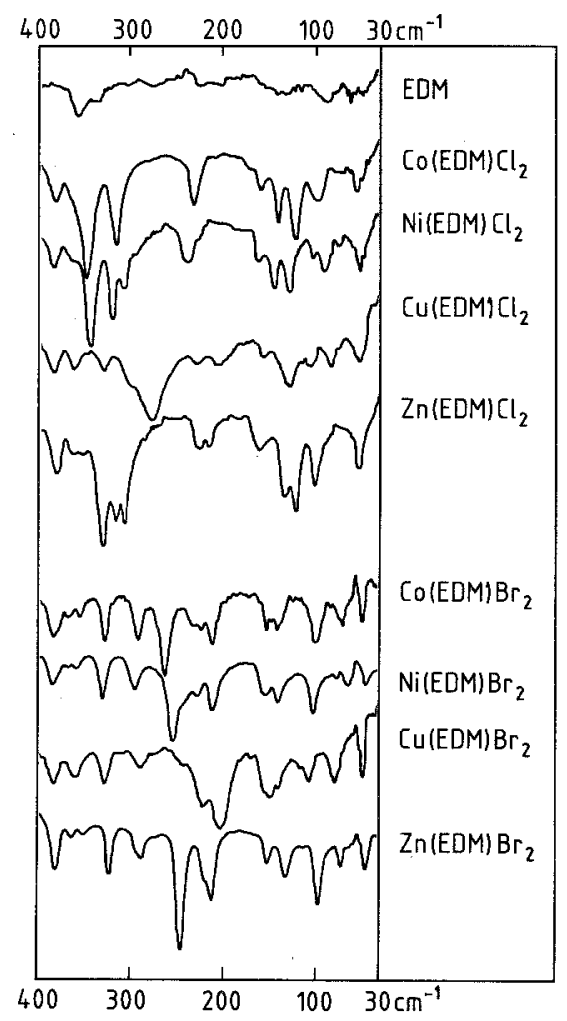

Figure 2. Raman spectra. 
straightforward comparisons along with mass shifts identify $v_{3}$ (symmetric metal-halogen stretch), $\left(\mathrm{M}-\mathrm{Cl}_{2}=305 \mathrm{~cm}^{-1}\right.$, $\mathrm{M}-\mathrm{Br}_{2}=209 \mathrm{~cm}^{-1}$ ) and $v_{9}$ (antisymmetric metal halogen stretch), (M-Cl $\left.=333 \mathrm{~cm}^{-1}, \mathrm{M}-\mathrm{Br}_{2}=247 \mathrm{~cm}^{-1}\right)$. Similarly, $v_{6}$ (metal-nitrogen asymmetric stretch) can be assigned, $\left(\mathrm{M}-\mathrm{N}_{2}\right.$ $\left.=324 \mathrm{~cm}^{-1}\right)$ and $v_{1}$ (metal-nitrogen symmetric stretch) $\left(\mathrm{M}-\mathrm{N}_{2}\right.$ $=296 \mathrm{~cm}^{-1}$ ). Each frequency is taken from the spectrum where it is most intense and well separated from other peaks, and in most cases is expected to be within $\pm 5 \mathrm{~cm}^{-1}$. By difference, the remaining peaks between $100-220 \mathrm{~cm}^{-1}$ in the chloride spectra must be due to the symmetrical $\mathrm{M}-\mathrm{N}_{2}$ bend $v_{2}$, and the torsion and rocking modes $v_{5}, v_{7}$, and $v_{8}$. It is tempting to assign these peaks, but here the neglect of the true lower symmetry makes the effort too speculative.

There are some changes in the spectra as a result of variation of the metal ion. In the series cobalt, nickel and zinc, the frequencies decrease for each type of vibration. These changes are small, however, and in the same direction as the shifts expected from the mass changes. Thus they cannot be distinguished from those expected from a crystal-field effect. With copper, the frequencies are substantially lower, in accord with the result of a Jahn-Teller type of distortion. These results are in substantial agreement with the assignments of Nakamoto and coworkers ${ }^{(4)}$, although the $\mathrm{M}-\mathrm{N}$ stretching frequencies are shomewhat higher in our compounds. This may be due to the morpholene group being somewhat less rigid than pyridine so that its group mass is effectively reduced.

\section{Experimental}

The compounds were prepared by methods previously described ${ }^{(5)}$. I.r. spectra were obtained from samples pressed into discs with spectral grade polyethylene at pressures of 400 $\mathrm{kg} / \mathrm{cm}^{2}$. The i.r. spectrometer was a Hitachi-Perkin Elmer FIS3 instrument, calibrated against $\mathrm{H}_{2} \mathrm{O}$ bands. Raman spectra were recorded from samples in capillaries using a Spex Model 1401 Ramalog spectrometer and $4880 \AA$ line of a $600 \mathrm{mw}$ argon ion laser.. I.r. spectra of all compounds used in this study were compared in the $4000-400 \mathrm{~cm}^{-1}$ region and found to be virtually identical. Thus the skeletal modes are to be found below $400 \mathrm{~cm}^{-1}$.

\section{Acknowledgement}

The author is grateful to members of Chem. Lab. IV of the H. C. Ørsted Institute, Copenhagen DK, for their hospitality during sabbatical leave and especially to Henning Vibaek for much helpful assistance. Support from the American Scandinavian Foundation as Henrik Kauffmann Fellow is gratefully acknowledged.

\section{References}

(1) D. M. Adams, Metal-Ligand and Related Vibrations, Arnold Ltd London, 1967. - ${ }^{(2)}$ R. J. H. Clark and C. S. Williams, Inorg. Chem., 4, 350 (1965). - ${ }^{(3)}$ A. Sabatini and L. Sacconi, J. Am. Chem. Soc., 86, 17 (1964). - ${ }^{(4)}$ Y. Saito, M. Cordes and K. Nakamoto, Spectrochim. Acta, 28A, 1459 (1972). - ${ }^{(5)}$ A. L. Lott and P. G. Rasmussen, $J$. Inorg. Nucl. Chem., 32, $101(1970) .-{ }^{(6)}$ W. R. Scheidt, J. C. Hanson and P. G. Rasmussen, Inorg. Chem., 8, 2398 (1969). - ${ }^{(7)}$ G. Herzberg, Infrared and Raman Spectroscopy, Vol. II of Molecular Spectra and Molecular Structure, Van Nostrand, Princeton NJ, 1945, p. 318. -

${ }^{(8)} \mathrm{H}$. Volkringer, J. LeComte and A. Tchakirian, J. de Physique, 105 (1938) . - ${ }^{(9)}$ H. Stammreich, K. Kawai and Y. Tavares, Spectrochim. Acta, 15, 438 (1959). - ${ }^{(10)}$ F. A. Miller, G. L. Carlson and W. B. White, Spectrochim. Acta, 15, 709 (1959).

${ }^{(11)}$ D. S. Alderdice, Ph.D. Thesis, University College, London, 1963 - ${ }^{(12)} \mathrm{K}$. Nakamoto, Infrared and Raman Spectra of Inorganic and Coordination Compounds, 3rd Edit. Wiley Interscience, New York 1978, p. 138. 212.

(Received April 15th, 1986)

TMC 1543

\title{
Magnetic Interactions in Spin-Labelled Glycine complexed to Cupric Ions
}

\author{
Colette Blaquiere* and Patrick Sharrock
}

Centre de Technologie Biomedicale (INSERM SC 13), Université Paul Sabatier, 38, Rue des Trente-Six Ponts, 31400 Toulouse, France

\section{Summary}

The interactions between cupric ions and a paramagnetic aminoacid ligand labelled with a nitroxide group were investigated by visible and e.p.r. spectroscopies. Glycine substituted on the carboxylic acid function with 4-amino-2,2,6,6-tetramethylpiperidine $N$-oxide forms complexes with cupric ions which show strong magnetic interactions between the paramagnetic centers. At high $\mathrm{pH}$ values, averaged $\mathrm{g}$ and hyperfine coupling parameters are observed with $\mathrm{g}=2.05$ and $\mathrm{a}=$ 30 gauss, corresponding to a complex formed with two ligands

\footnotetext{
* Author to whom all correspondence should be directed.
}

coordinated to the cupric ions. The presence of other species is discussed.

\section{Introduction}

We recently reported the synthesis of various spin-labelled biomolecules ${ }^{(1)}$. Paramagnetic cupric ions or complexes interact with aminoalcohol spin labels in aqueous solutions, mainly affecting the relaxation times of the organic radicals ${ }^{(2)}$. A variety of complexes can be made with ligands containing a nitroxide spin label. Several reports exist of addition compounds formed with simple nitroxides ${ }^{(3-6)}$, but most work is 